\title{
Serum Level of Homocysteine and Perinatal CNS Lesions in Infants
}

\author{
Olga N. Krasnorutskaya, PhD*; Vera S. Lednyova, PhD, ScD; \\ Anna A. Zuikova, PhD, ScD; Alexander N. Pashkov, PhD, ScD; \\ Daniel Yu. Bugrimov, PhD; Julia A. Kotova, PhD; Elena Yu. Esina, PhD \\ Voronezh State Medical University named after N.N. Burdenko \\ Voronezh, the Russian Federation
}

\begin{abstract}
This study reports an assessment of adaptive possibilities of the central nervous system (CNS) in infants. The study shows how the homocysteine level depends on the severity of neurological deficit (ND) in infants, and how the serum homocysteine level changes during the various treatment regimens. (International Journal of Biomedicine. 2017;7(4):286-288.)
\end{abstract}

Key words: neurological deficit $\bullet$ homocysteine $\bullet$ CNS $\bullet$ infants

\section{Introduction}

A number of perinatal pathological factors, primarily hypoxic and ischemic, are important causes of CNS damage in early childhood. ${ }^{(1)}$ A sensitive indicator of brain damage is homocysteine (Hcy). ${ }^{(2)} \mathrm{Hcy}$ is a non-protein-forming, sulfurcontaining amino acid that functions as a key intermediate in methionine metabolism. Met is first demethylated to form Hcy, which is then metabolized through two pathways: transsulfuration to cysteine and remethylation to methionine. Deficiency in Hcy metabolic enzymes could lead to abnormal Hcy level. Hyperhomocysteinemia is defined as a medical condition characterized by an abnormally high level (above $15 \mu \mathrm{mol} / \mathrm{L}$ ) of homocysteine in the blood. ${ }^{(3)}$

Elevated Hcy is associated with an increased risk of occlusive vascular disease, birth defects (neural tube defects), complications during pregnancy, and psychiatric disorders. ${ }^{(4,5)}$

Hcy influences the fetus in the early stages, through disordered brain structure development and function, and/or through placenta vascularization disorders, which reduces the oxygen feed to the fetus. ${ }^{(6)}$

Hyperhomocysteinemia may arise from genetic defects of enzymes involved in homocysteine metabolism. The enzymes involved can be 5,10-methylene tetrahydrofolate

*Corresponding author: Olga N. Krasnorutskaja, PhD. Voronezh State Medical University named after N.N. Burdenko. Voronezh, the Russian Federation. E-mail: onkrasnorutckaja@ rambler.ru reductase, methionine synthase, and cystathionine- $\beta$-synthase. Hyperhomocysteinemia can also arise from nutritional deficiencies of folate, vitamin $\mathrm{B}_{6}$, and vitamin $\mathrm{B}_{12}{ }^{\cdot(7)}$

Based on the blood homocysteine level, we aimed to generate the criteria for evaluating ND development and outcome in infants after different treatment approaches.

\section{Materials and Methods}

The study included 419 patients (52\% boys and $48 \%$ girls) aged from 0 to 6 months. The main group (Group 1) included 336 patients in the first year of life who received inpatient treatment because of perinatal CNS damage of a different degree of severity. The control group (Group 2) included 83 apparently healthy children. Children in the control group passed standard clinical examinations in specified periods of observation at the stage of outpatient services.

There were several obligatory criteria for patients to be included in the control group: absence of neurological symptoms, absence of a neurologist's supervision, and pharmacotherapy of neurological deviations during the first year of life.

Groups 1 and 2 were divided into two subgroups according to age: Group 1a $(n=163)$ and Group 2a $(n=43)$ between the ages of 1 to 3 months; Group $1 \mathrm{~b}(\mathrm{n}=173)$ and Group $2 \mathrm{~b}(\mathrm{n}=40)$ between the ages of 4 to 6 months. In accordance with the ND severity, the main group was also divided into subgroups: mild degree ( $\mathrm{I}, \mathrm{n}=122)$, moderate 
degree (II, $\mathrm{n}=118$ ), and severe degree (III, $\mathrm{n}=96$ ).

All of the children underwent a somatic and neurological examination. To assess the damage to the nervous system, YA Yakunin's classification (1979) was used. ND was evaluated by a quantitative method based on the 3 points according to the severity (0 - norm, 1 - mild, 2 - moderate, and 3 - severe ND).

The serum level of Hcy was determined by enzyme immunoassay using «Axis-Shield» test kit.

In accordance with a treatment regimen, the main group was also divided into 2 subgroups: subgroup A $(n=170)$, patients who received therapy depending on a general clinical manifestation; and subgroup B $(n=166)$, patients, who received therapy depending on a dominant syndrome (increased intracranial pressure - ICP). The treatment regimens are presented in Table 1.

\section{Table 1.}

The prescribed schemes of therapy in the studied groups

\begin{tabular}{|c|c|c|c|c|c|c|}
\hline \multirow{3}{*}{ 告 } & \multicolumn{2}{|c|}{$\begin{array}{l}\text { Mild degree } \\
\text { of ND (I) }\end{array}$} & \multicolumn{2}{|c|}{$\begin{array}{l}\text { Moderate degree } \\
\text { of ND (II) }\end{array}$} & \multicolumn{2}{|c|}{$\begin{array}{l}\text { Severe degree } \\
\text { of ND (III) }\end{array}$} \\
\hline & \multicolumn{6}{|c|}{ Subgroup } \\
\hline & A & B & A & B & A & B \\
\hline $1-3$ & $\begin{array}{c}\text { Scheme D } \\
(\mathrm{n}=30)\end{array}$ & $\begin{array}{c}\text { Scheme B } \\
(\mathrm{n}=29)\end{array}$ & $\underset{(n=30)}{\text { Scheme D }}$ & $\begin{array}{l}\text { Scheme A } \\
(\mathrm{n}=29)\end{array}$ & $\underset{(n=24)}{S}$ & $\mid \begin{array}{c}\text { Scheme C } \\
(\mathrm{n}=21)\end{array}$ \\
\hline $4-6$ & $\begin{array}{c}\text { Scheme D } \\
(\mathrm{n}=31)\end{array}$ & $\begin{array}{c}\text { Scheme B } \\
(\mathrm{n}=32)\end{array}$ & $\begin{array}{c}\text { Scheme D } \\
(\mathrm{n}=30)\end{array}$ & $\begin{array}{c}\text { Scheme A } \\
(\mathrm{n}=29)\end{array}$ & $\begin{array}{c}\text { Scheme D } \\
(\mathrm{n}=25)\end{array}$ & $\underset{(n=26)}{\text { Scheme C }}$ \\
\hline
\end{tabular}

Scheme A: neuroprotector cortexin + drugs for correction of increased ICP

Scheme B: vasoactive agent vinpocetine + vitamin therapy (folic acid + B-group vitamins) + drugs for correction of increased ICP

Scheme C: nootropic and vasoactive drugs, central muscle relaxants drugs for correction of increased ICP, vitamins and biogenic stimulators
During treatment, we used therapeutic agents with various degrees of nootropic effect, and vasoactive agents. For correction of spasticity, drugs with muscle relaxant effect were used (sirdalud, baclofen, mydocalm). For correction of increased ICP, we used diacarb, triampur and magnesium sulfate. The study was approved by the Voronezh State Medical University Ethics Committee. Written informed consent was obtained from the child's parents.

Statistical analysis was performed using StatSoft Statistica v6.0. Baseline characteristics were summarized as frequencies and percentages for categorical variables and as mean \pm SD for continuous variables. Student's unpaired and paired t-tests were used to compare two groups for data with normal distribution. Multiple comparisons were performed with one-way ANOVA and post-hoc Tukey HSD test. A probability value of $\mathrm{P}<0.05$ was considered statistically significant.

\section{Results and Discussion}

Analyzing the frequency of clinical neurological manifestations in the main group, we found that the dominant neurological syndrome was increased ICP (91\%).

In the control group, the serum level of Hcy (Table 2) did not differ significantly in Group 2a and Group 2b. In all subgroups of Group 1, the average Hcy level significantly increased compared to the control group. However, a more pronounced increase of the Hcy level was found in Group $1 \mathrm{~b}$.

ANOVA showed a main effect of the ND severity $(\mathrm{P}<0.000)$ in both age groups. In fact, post-hoc comparisons between groups revealed a decrease in the Hcy levels with the severity of ND. These results reflect the association between Hcy level and the ND severity.

In patients with mild clinical manifestations of ND in Group 1a, the serum level of Hcy showed statistically significant positive dynamics during treatment, both in subgroups A and B, but serum level of Hcy reached the control level of healthy infants only in subgroup A (Table 2).

Table 2.

The serum level of Hcy $(\mu \mathrm{mol} / \mathrm{ml})$ in the studied groups

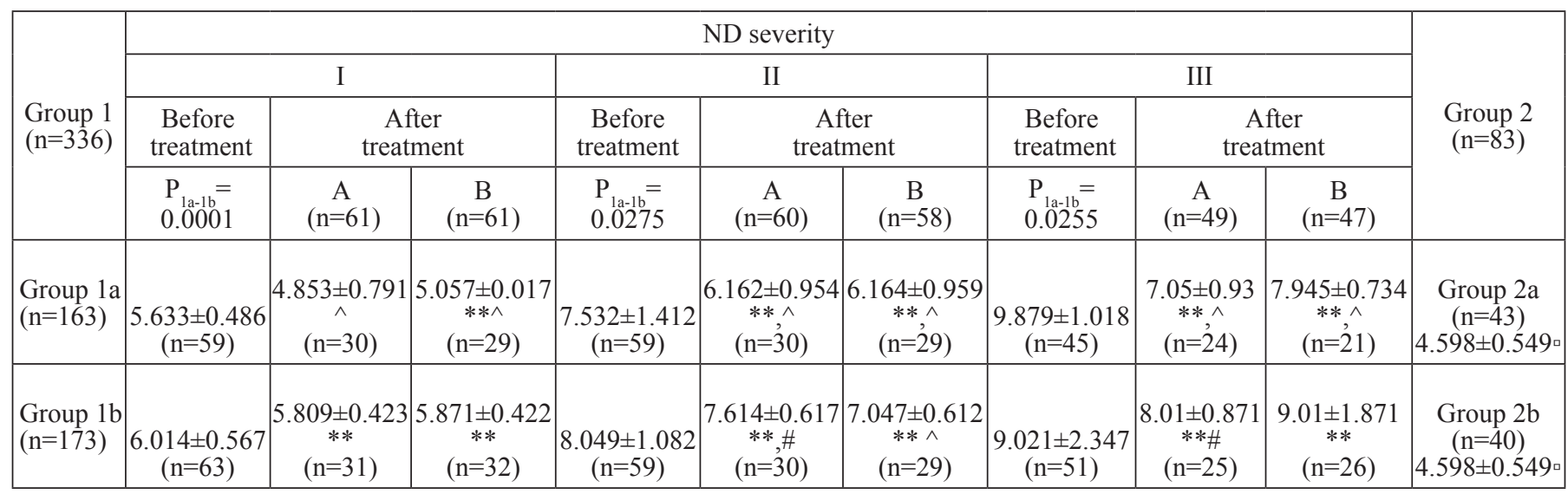

$* *-P=0.000$ compared to Group $2(a / b) ; \#-P<0.05$ compared before treatment in each ND group;

$\wedge-P=0.000$ compared before treatment in each $N D$ group;

$-P=0.0000(F=274.9314$ and $F=112.7278)$ compared to Group 1 a $(I, I I, I I I)$ and Group $1 b(I, I I, I I I)$ before treatment;

Group la: $F=210.5429, P=0.0000$ (differences between I, II, III) before treatment

Group 1b: $F=63.9604, P=0.0000$ (differences between I, II, III) before treatment. 
In patients with mild clinical manifestations of ND in Group 1b, the serum level of Hcy showed only a positive trend, both in subgroups A and B, and serum level of Hcy did not reach the control level of healthy infants. Thus, we found an age-related effect on the Hcy level during treatment.

In patients with moderate clinical manifestations of ND in all age subgroups of Group 1, the decrease of serum Hcy level was statistically significant during provided therapy, both in subgroups A and B. However, a more pronounced decrease of the Hcy level was found in Group 1a, but serum level of Hcy did not reach the control level of healthy infants. Thus, with age and intensification of ND severity, the positive effect on the serum Hcy level decreases regardless of the treatment scheme.

The minimal changes in the serum Hcy level were found in patients with severe clinical manifestations of ND in Group 1b. The serum Hcy level did not change significantly during treatment in subgroup B.

Thus, the character of the dynamics of the serum Hcy level during ND therapy in children of the first year of life can reflect the age-related features of the pathological process and the adequacy of therapy.

\section{Competing interests}

The authors declare that they have no competing interests.

\section{References}

1. Hagberg H, David Edwards A, Groenendaal F. Perinatal brain damage: The term infant. Neurobiol Dis. 2016;92(Pt A):102-12. doi: 10.1016/j.nbd.2015.09.011.

2. Harteman JC, Groenendaal F, Benders MJ, Huisman A, Blom HJ, de Vries LS. Role of thrombophilic factors in fullterm infants with neonatal encephalopathy. Pediatr Res. 2013 Jan;73(1):80-6. doi: 10.1038/pr.2012.150.

3. Guo H, Chi J, Xing Y, Wang P. Influence of folic acid on plasma homocysteine levels \& arterial endothelial function in patients with unstable angina. Indian J Med Res. 2009;129(3):279-84.

4. Murray CJ, Lopez AD. The Global Burden of Disease: A Comprehensive Assessment of Mortality and Disability from Disease, Injuries and Risk Factors in 1990 and projected to 2020. Harvard School of Publics Health, Boston, Mass, USA; 1996. 5. Kevere L, Purvina S, Bauze D, Zeibarts M, Andrezina R, Rizevs A, et al. Elevated serum levels of homocysteine as an early prognostic factor of psychiatric disorders in children and adolescents. Schizophr Res Treatment. 2012;2012:373261. doi: 10.1155/2012/373261.

6. Bolander-Gouaille C, Bottiglieri T. Homocysteine Related Vitamins and Neuropsychiatric Disorders. Springer, Paris, France, 2nd edition; 2007.

7. Curro M, Gugliandolo A, Gangemi C, Risitano R, Ientile R, Caccamo D. Toxic effects of mildly elevated homocysteine concentrations in neuronal-like cells. Neurochem Res. 2014;39:1485-95. doi: 10.1007/s11064-014-1338-7. 